\title{
RESEARCH
}

Open Access

\section{Human amniotic mesenchymal stem cells- conditioned medium protects mice from high-fat diet-induced obesity}

Hui-Lan Tan ${ }^{1,2+}$, Xiao-Hui Guan ${ }^{1 \dagger}$, Min Hu' ${ }^{1}$, Jie Wu ${ }^{1,3}$, Rong-Zhen Li ${ }^{1,3}$, Ling-Fang Wang ${ }^{1}$, Hou-Da Huang ${ }^{1}$, Zhen-Ping Yu ${ }^{1,3}$, Xiao-Yu Wang ${ }^{1,3}$, Yun-Fei Xiao ${ }^{1}$, Ke-Yu Deng ${ }^{1,2,3^{*}}$ and Hong-Bo Xin ${ }^{1,2,3^{*}}$ (D)

\begin{abstract}
Background: Obesity is a metabolic disorder syndrome characterized by excessive fat accumulation that is related to many diseases. Human amniotic mesenchymal stem cells (hAMSCs) have a great potential for cell-based therapy due to their characteristics such as pluripotency, low immunogenicity, no tumorigenicity, potent paracrine effects, and no ethical concern. Recently, we observed that both hAMSCs and their conditioned medium (hAMSCs-CM) efficiently repaired skin injury, inhibited hepatocellular carcinoma, and alleviated high-fat diet (HFD)-induced diabetes. However, the effects and the underlying mechanisms of hAMSCs-CM on high-fat diet (HFD)-induced obesity were not explored.
\end{abstract}

Methods: The characteristics of hAMSCs were confirmed by flow cytometry, RT-PCR, and immunofluorescence. Obese mice were induced by administrating HFD for 15 weeks and simultaneously, the mice were intraperitoneally injected with hAMSCs-CM weekly to evaluate the effects of hAMSCs-CM on HFD-induced obesity. GTT and ITT assays were used to assess the effects of hAMSCs-CM on HFD-induced glucose tolerance and insulin resistance. The lipid accumulation and adipocytes hypertrophy in mouse adipose tissues were determined by histological staining, in which the alterations of blood lipid, liver, and kidney function were also examined. The role of hAMSCs-CM in energy homeostasis was monitored by examining the oxygen consumption $\left(\mathrm{VO}_{2}\right)$, carbon dioxide production $\left(\mathrm{VCO}_{2}\right)$, and food and water intake in mice. Furthermore, the expressions of the genes related to glucose metabolism, fatty acid $\beta$ oxidation, thermogenesis, adipogenesis, and inflammation were determined by western blot analysis, RT-PCR, and immunofluorescence staining. The roles of hAMSCs-CM in adipogenesis and M1/M2 macrophage polarization were investigated with 3T3-L1 preadipocytes or RAW264.7 cells in vitro.

\footnotetext{
* Correspondence: dky@ncu.edu.cn; xinhb@ncu.edu.cn

${ }^{\dagger}$ Hui-Lan Tan and Xiao-Hui Guan contributed equally to this work.

${ }^{1}$ The National Engineering Research Center for Bioengineering Drugs and the Technologies, Institute of Translational Medicine, Nanchang University, No. 1299 Xuefu Road, Honggutan District, Nanchang 330031, China Full list of author information is available at the end of the article
}

C C The Author(s). 2021 Open Access This article is licensed under a Creative Commons Attribution 4.0 International License, which permits use, sharing, adaptation, distribution and reproduction in any medium or format, as long as you give appropriate credit to the original author(s) and the source, provide a link to the Creative Commons licence, and indicate if changes were made. The images or other third party material in this article are included in the article's Creative Commons licence, unless indicated otherwise in a credit line to the material. If material is not included in the article's Creative Commons licence and your intended use is not permitted by statutory regulation or exceeds the permitted use, you will need to obtain permission directly from the copyright holder. To view a copy of this licence, visit http://creativecommons.org/licenses/by/4.0/ The Creative Commons Public Domain Dedication waiver (http://creativecommons.org/publicdomain/zero/1.0/) applies to the data made available in this article, unless otherwise stated in a credit line to the data. 
Results: hAMSCs-CM significantly restrained HFD-induced obesity in mice by inhibiting adipogenesis and lipogenesis, promoting energy expenditure, and reducing inflammation. The underlying mechanisms of the antiobesity of hAMSCs-CM might be involved in inhibiting PPARY and C/EBPa-mediated lipid synthesis and adipogenesis, promoting GLUT4-mediated glucose metabolism, elevating UCP1/PPARa/PGC1a-regulated energy expenditure, and enhancing STAT3-ARG1-mediated M2-type macrophage polarization.

Conclusion: Our studies demonstrated that hAMSCs significantly alleviated HFD-induced obesity through their paracrine effects. Obviously, our results open up an attractive therapeutic modality for the prevention and treatment of obesity and other metabolic disorders clinically.

Keywords: Obesity, hAMSCs-CM, Energy expenditure, Lipid metabolism, Glucose metabolism, Inflammation

\section{Background}

Obesity is a metabolic disorder syndrome characterized by excessive fat accumulation in the body due to excessive food intake or the alteration of lifestyle and it is a risky factor for many diseases such as diabetes and cardiovascular diseases $[1,2]$. In general, the occurrence of obesity is closely related with energy homeostasis, lipogenesis, and inflammation [3].

Metabolic disorder is a predisposition factor of obesity. Peroxisome proliferator-activated receptors $\alpha$ (PPAR $\alpha)$ and PPAR-coactivator $1 \alpha(\mathrm{PGCl} \alpha)$ play an important role in energy homeostasis such as fatty acid $\beta$ oxidation and gluconeogenesis $[4,5]$. It has been reported that fasted $\mathrm{PPAR}^{-1-}$ mice were not able to sufficiently catabolize lipids in the liver and finally resulted in steatosis [6]. Glucose is a main energy source for mitochondrial metabolism especially in adipose and muscle tissues. In dysfunctional adipose tissues, the expressions of glucose transporters (GLUTs) were remarkably decreased, resulting in insulin resistance-induced hyperglycemia [7]. Hence, correction of energy homeostasis disorder is an effective way to prevent obesity.

Adipose tissues include white adipose tissues (WAT) and brown adipose tissues (BAT) which possess different functions [8]. WAT primarily serves as an important organ for energy storage, but also is able to secrete numerous hormones in response to nutritional signals [9]. In contrast, $\mathrm{BAT}$, as a thermogenic organ, is responsible for converting calorie to heat in cold circumstances [10], in which the processes are mainly mediated by activating mitochondrial uncoupling protein 1 (UCP1) which is a mitochondrial protein uncoupling cellular respiration and ATP synthesis to dissipate energy as heat [11]. Therefore, BAT inhibits obesity or obesity-related metabolic diseases by promoting glucose and lipid consumption [12]. PPAR $\gamma$, carbohydrate response element-binding protein (C/EBP), and sterol response element-binding protein 1c (SREBP1c) are vital transcriptional regulators in adipogenesis $[4,13,14]$. WAT, as a secretory organ, plays a crucial role in the adipose tissue inflammation by secreting numerous adipokines to recruit macrophages into the tissues $[15,16]$. Studies also revealed that eliminating the adipose tissues inflammation could alleviate obesity [17]. Therefore, several strategies such as enhancing energy expenditure, inhibiting adipogenesis, and reducing adipose tissues inflammation can be used for preventing or treating obesity.

Studies showed that mesenchymal stem cells (MSCs)derived conditioned medium (CM) and exosomes contained abundant cytokines, growth factors, extracellular matrix proteins, chemokines, and nuclear acids [18]. It has been reported that MSCs-CM effectively treated many diseases such as pulmonary disease, hair regrowth, diabetes, liver fibrosis, hepatoma carcinoma, osteoarthritis by inhibiting inflammation, and promoting immuno-regulation [19-22].

Human amniotic mesenchymal stem cells (hAMSCs) are considered as a promising source of stem cells for cell-based therapy due to their characteristics such as pluripotency, low immunogenicity, no tumorigenicity, potent paracrine effects, and no ethical concern [23]. Previously, we observed that both hAMSCs and their CM efficiently repaired skin injury [24], inhibited hepatocellular carcinoma [25], and alleviated HFD-induced hyperglycemia in mice (unpublished data). It has been reported that adipose MSC-derived exosomes ameliorated HFD-induced obesity in mice through inhibiting inflammation, improving insulin sensitivity, and decreasing hepatic steatosis [26, 27]. However, the effect of hAMSCs$\mathrm{CM}$ on HFD-induced obesity in mice was not explored. Based on the advantages of hAMSCs in the cell-based therapy and the complexity of obesity, we hypothesized that hAMSCs-CM might alleviate HFD-induced obesity through affecting energy expenditure, inhibiting adipogenesis, and reducing adipose tissue inflammation. Obviously, our results would provide a new insight in elucidating the mechanism of the anti-obesity of hAMSCs-CM and a new strategy for the prevention and treatment of metabolic disorder-related diseases such as obesity clinically.

\section{Methods}

Isolation, culture, and characterization of hAMSCs

Human amniotic membrane tissue of the placenta was obtained from healthy pregnant women (38-41 weeks) 
after they gave their births or when they were undergoing cesarean delivery in the First Affiliated Hospital of Nanchang University. Informed consent was obtained from women who voluntarily donated their placentas. The obtained tissue samples were only used for scientific research, not for commercial and reproductive ethicsrelated research and development. The research procedure was approved by the ethics committee of the First Affiliated Hospital of Nanchang University.

hAMSCs were isolated and cultured as described [24, 28]. Briefly, amnions isolated from human placenta were cut into small pieces and washed with D-Hanks buffer containing $100 \mathrm{U} / \mathrm{mL}$ penicillin and $100 \mu \mathrm{g} / \mathrm{mL}$ streptomycin and then digested with $0.25 \%$ trypsin-EDTA and type IV collagenase $(1 \mathrm{mg} / \mathrm{mL}$; Worthington, Lakewood, NJ) respectively. Then, the cells were cultured in athe complete medium. The supernatants were discarded after $5 \mathrm{~h}$ incubation. The adherent cells were continued to be maintained in a complete medium at $37^{\circ} \mathrm{C}$ with $5 \% \mathrm{CO}_{2}$.

The hAMSCs were harvested to identify the immunophenotype using PE-conjugated anti-CD45, anti-CD90, anti-CD105, anti-CD29, and anti-CD40 antibodies and FITC-conjugated anti-CD73, anti-CD34, anti-ABC, antiCD80, and anti-HLA-DR antibodies (all antibodies purchased from BD Biosciences) by flow cytometry analysis. The characteristics of hAMSCs were also confirmed by RT-PCR and immunofluorescence.

\section{Preparation of hAMSCs-CM}

The complete medium of hAMSCs was replaced with the serum-free DMEM (SFD) when the cell density reached to $80-90 \%$ confluence. The supernatants were collected after $48 \mathrm{~h}$ and centrifuged at $1500 \mathrm{rpm}$ for 5 min to remove all cellular debris, and the cell numbers were counted. The supernatant which was referred as hAMSCs-CM were further concentrated with a Millipore centrifuge tube (Millipore, UFC900324) and stored at $-80^{\circ} \mathrm{C}$ for future experiments.

\section{Experimental animals}

Six- to 8-week-old male C57BL/6 mice (Hunan SJA Laboratory Animal Co, Ltd.) were fed with a normal chow diet (CHOW-D, Jiangsu Xietong Pharmaceutical Bioengineering Co, Ltd, C00105) or high-fat diet (HFD, D12492, 60\% kcal from fat, Research Diet, USA) for 15 weeks, in which the mice were housed in a temperature $\left(20-24{ }^{\circ} \mathrm{C}\right)$ and humidity-controlled (45-55\%) individual ventilated cages with a $12 \mathrm{~h} / 12 \mathrm{~h}$ light/dark cycle. Mice were randomly assigned into 3 groups, hAMSCs-CMtreated group with HFD $(\mathrm{n}=6)$, SFD-treated group with HFD ( $n=6)$, CHOW-D group $(n=5)$, and were intraperitoneally injected with hAMSCs-CM suspended in $0.4 \mathrm{~mL}$ DMEM (for hAMSCs-CM group) or $0.4 \mathrm{~mL}$ SFD alone (for SFD group) for 15 weeks. Fasting body weight was monitored weekly. The final administrated concentration of hAMSCs-CM for each mouse was defined as a concentration which was equivalent to the collected conditional medium of $1.5 \times 10^{6}$ cells cultured in serum-free medium for $48 \mathrm{~h}$.

\section{Energy expenditure measurement}

Mice were accustomed into the metabolic chambers for more than $24 \mathrm{~h}$ before performing the measurement of metabolic parameters and then the oxygen consumption $\left(\mathrm{VO}_{2}\right)$, carbon dioxide production $\left(\mathrm{VCO}_{2}\right)$, and food and water intake were monitored for $48 \mathrm{~h}$ in animal monitoring system TSE PhenoMaster (Germany, TSE Systems) following the instruction of the manufacturer.

Glucose tolerance test (GTT) and insulin tolerance test (ITT) GTT and ITT were performed in mice by injection of glucose $(2 \mathrm{~g} / \mathrm{kg})$ or insulin $(0.5 \mathrm{U} / \mathrm{kg})$, intraperitoneal injection (I.P.) after the mice were fasted for $16 \mathrm{~h}$ or $4 \mathrm{~h}$, respectively, and the tail capillary blood glucose concentrations were measured with a glucometer (Sinocare, GA-3) at indicated times.

\section{Biochemical analysis}

Serum alanine transaminase (ALT), aspartate aminotransferase (AST), total cholesterol (TC), triglyceride (TG), high-density lipoprotein cholesterol (HDL-C), low-density lipoprotein cholesterol (LDL-C), total protein (TP), creatinine (CREA), and blood urine nitrogen (BUN) were detected using automatic biochemical analyzer (Beckman Coulter AU2700) according to Beckman AU clinical biochemical reagent.

\section{Immunofluorescence staining}

WAT and BAT were fixed with 4\% PFA (Solarbio, Beijing, P1110) and embedded in paraffin. The 4- $\mu \mathrm{m}$ sections were prepared, followed by deparaffinization, rehydration, and quenching endogenous peroxidases with $0.3 \% \mathrm{H}_{2} \mathrm{O}_{2}$ (in PBS) for $10 \mathrm{~min}$. Then the tissue sections were incubated with antigen retrieval buffer (Solarbio, C1032) at $95^{\circ} \mathrm{C}$ for $20 \mathrm{~min}$ and were permeabilized by $0.1 \%$ Triton X-100 and incubated with anti-F4/80 antibody (Abcam, 1:100, ab6640) and UCP1 antibody (Abcam, 1:500, ab23841) overnight at $4{ }^{\circ} \mathrm{C}$ followed by incubating with a secondary antibody goat anti-rat IgG H\&L (Alexa Fluor ${ }^{\circ} 488$ ) and goat anti-rabbit IgG H\&L (Alexa Fluor ${ }^{\circ}$ 647) for 60 min. Nuclei were stained with DAPI (Solarbio, S2110). hAMSCs were fixed with $4 \%$ PFA for $30 \mathrm{~min}$ at RT and blocked with $10 \%$ goat serum for $60 \mathrm{~min}$. Primary antibodies against SSEA4 (Abcam, 1: 100, ab16287) or Vimentin (Proteintech, 1:200, 10366-1AP) were then incubated overnight at $4{ }^{\circ} \mathrm{C}$. After that, cells were incubated with secondary antibody goat antimouse or anti rabbit (Alexa Fluor ${ }^{\circ} 488$ ) for $60 \mathrm{~min}$. 


\section{Hematoxylin-eosin (HE) staining}

Adipose tissues were isolated from the mice and fixed with $4 \%$ PFA overnight. The tissues embedded in paraffin were sectioned into $4 \mu \mathrm{m}$ thickness, followed by deparaffinization, rehydration, and finally stained with hematoxylin and eosin following the manufacturer's introductions (Solarbio, Beijing, G1121).

\section{Periodic acid-Schiff (PAS) staining}

Liver sections were rehydrated according to the HE staining procedures and washed with PBS and incubated with Schiff reagent (Solarbio, Beijing, G1280) for $15 \mathrm{~min}$. After rinsing with distilled water for $2 \mathrm{~min}$, the sections were dyed with hematoxylin, and glycogen deposition in the liver was showed in purple.

\section{Cell culture}

Pre-adipocytes cell line 3T3-L1 and RAW264.7 cells were purchased from Stem Cell Bank, Chinese Academy of Sciences. 3T3-L1 cells were cultured with DMEM (Gibco, C11995500BT) containing 10\% new bovine serum. RAW264.7 cells were cultured with RPMI-1640 (Gibco, C1187500BT) containing 10\% fetal bovine serum (BI, 04004-1A). hAMSCs were cultured in MEM- $\alpha$ (Gibco, A10490-01) containing 10\% fetal bovine serum (Gibco, 10099-141), 2\% Chang C (IrvineScientific, C108), 18\% Chang B (IrvineScientific, C100), 0.1\%FGF-basic $(20 \mathrm{ng} / \mathrm{mL}$, Peprotech, 100-1B), 1\% L-GLU (Gibco, 35050061), and 0.1\% $\beta$ Mercaptoethanol (Solarbio, Beijing, 21985023). All cells were cultured with $100 \mathrm{U} / \mathrm{mL}$ penicillin and $100 \mathrm{mg} / \mathrm{mL}$ streptomycin and maintained at $37{ }^{\circ} \mathrm{C}$ in a humidified incubator under $5 \% \mathrm{CO}_{2}$. One hundred $\mathrm{ng} / \mathrm{mL}$ LPS (Sigma-Aldrich, L4130), $2.5 \mathrm{ng} / \mathrm{mL}$ IFN- $\gamma$ (Novoprotein, C746), and $10 \mu \mathrm{g} /$ mL IL-4 (Novoprotein, CK74) were used in the experiments of RAW264.7 cells.

\section{Differentiation of 3T3-L1 pre-adipocytes}

3T3-L1 preadipocytes were cultured and maintained in DMEM containing $10 \%$ fetal calf serum. When the cells reached to $100 \%$ confluence, the $3 \mathrm{~T} 3-\mathrm{L} 1$ preadipocytes were cultured for another $48 \mathrm{~h}$. Then the differentiation of 3T3-L1 preadipocytes were induced with an induction medium containing $0.5 \mathrm{mM}$ IBMX (Sigma-Aldrich, 15879), $1 \mu \mathrm{M}$ dexamethasone (Solarbio, Beijing, D8040), and $10 \mu \mathrm{g} / \mathrm{mL}$ insulin (Jiangsu Wanbang Biopharmaceutical Co, Ltd.) for 2 days. Subsequently, the cells were maintained in an adipocyte culture medium supplemented with $10 \mu \mathrm{g} / \mathrm{mL}$ insulin for another 2 days and replaced with fresh 10\% FBS complete medium every 2 days. After 14 days induction, obvious cellular lipid droplets were observed.

\section{Oil Red $O$ staining}

Liver tissues were fixed in 4\% PFA and then were gradually incubated in gradient sucrose solutions $(30 \%, 50 \%$, and $70 \%$ sucrose) for more than $12 \mathrm{~h}$ until liver tissues sank into the bottom, and then the tissues were embedded with OCT compound (Tissue Tek, 4583) and 8- $\mu \mathrm{m}$ frozen sections were used for Oil Red $\mathrm{O}$ staining (Sigma-Aldrich, 1320-06-5). The differentiated mature adipocytes were washed with PBS and fixed with $4 \%$ PFA overnight and the cells were incubated with working Oil Red O solution (in 60\% isopropanol) for $10 \mathrm{~min}$. After washing twice with PBS, the cells were visualized under an inverted microscope (Olympus, Tokyo, Japan).

\section{RNA isolation, CDNA synthesis, and quantitative real-time PCR}

Total RNAs from adipose tissues or cells were isolated using TRIzol reagent (Life technology, 15596018) according to the manufacturer's instructions. Singlestranded cDNA were synthesized with a reverse transcription kit (Thermo Fisher Scientific, K1622). mRNA levels were measured by qRT-PCR with SYBR-RT-PCR master mix (Roche, USA) with ABI ViiA7 PCR machine (Applied Biosystems, USA). GAPDH was used as a loading control. The analyses of the related gene expressions were performed with the relative quantification comparative CT method. The primer sequences for qRTPCR were shown in Supplementary Tab. 1.

\section{Western blot}

Adipose tissues were lysed with RIPA buffer (Solarbio, Beijing, R0010), and protein concentrations were determined by a BCA Protein Assay Kit (Thermo Fisher Scientific, 23227). Each sample containing $40 \mu \mathrm{g}$ protein was loaded in SDS PAGE gel for western blot analyses and the primary antibodies were used as follows: SREBP1 (Santa Cruz, rabbit,1:250, sc-8984), PPARy (Santa Cruz, mouse, 1:250, sc-7273), FASN (Abcam, ab128870, 1:5000), C/ EBPa (Santa Cruz, rabbit, AF6333, 1:500), GLUT4 (1: 1000, rabbit, CST, 2213), P-AKT (1:1000, rabbit, CST, \#9272), AKT (1:1000, rabbit, CST, \#4060), PPAR $\alpha$ (Santa Cruz, mouse, sc-398394, 1:1000), PGC1 $\alpha$ (Santa Cruz, rabbit, sc-13067, 1:1000), ARG-1 (1:1000, rabbit, CST, $93668 \mathrm{~s})$, STAT3 (1:1000, rabbit, CST, 4904 s), P-STAT3 (1:1000, rabbit, CST, 9145), $\beta$-actin (1:5000, mouse, ABclonal, AC004), and GAPDH (1:10000, mouse, KANG CHEN, KC-5G4). The secondary antibodies were used as follows: HRP-conjugated goat anti-rabbit (1:5000, Thermo Fisher Scientific, 31460) and goat anti-mouse (1:5000, Thermo Fisher Scientific, 31430) antibodies. $\beta$-actin or GAPDH was used as a reference control. Signals were detected using the ECL Plus detection system (Thermo Fisher Scientific) and the images were quantified with ImageJ software. 


\section{Statistical analysis}

The results were expressed as means $\pm \mathrm{SD}$ (standard deviation). The statistical analysis was carried out using the Graphpad Primer 5 software. Differences between groups were assessed using Student's t tests (two samples) or one-way ANOVA (three or more samples). For all analyses, the statistical significance level was set at $" p\left|I^{\#} p<0.05 ;{ }^{* * *} p\right|^{\# \#} p<0.01,\left.{ }^{* * * *} p\right|^{\# \# \# p} p<0.001$.

\section{Results}

\section{Characteristics of hAMSCs}

hAMSCs were isolated from the human amniotic membrane as previously described [24] and the hAMSCs have a typical bipolar spindle-like and fibroblastic-shaped morphology (Fig. 1A). Flow cytometry showed that hAMSCs expressed mesenchymal stem cells (MSCs) surface markers including CD73, CD90, CD29, and CD105, as well as human leukocyte antigen class I (HLA-I ABC). However, hAMSCs did not express CD40, CD80, HLAII DR, and hematopoietic stem cell (HSC) markers CD34 and CD45 (Fig. 1B). RT-PCR assay further confirmed that hAMSCs did express the embryonic stem cell (ESC) markers (SOX2, Nanog, OCT4) and MSC markers (CD29, CD90, CD73, CD105), but not express HSC markers (CD34 CD133, CD45) (Fig. 1C). In

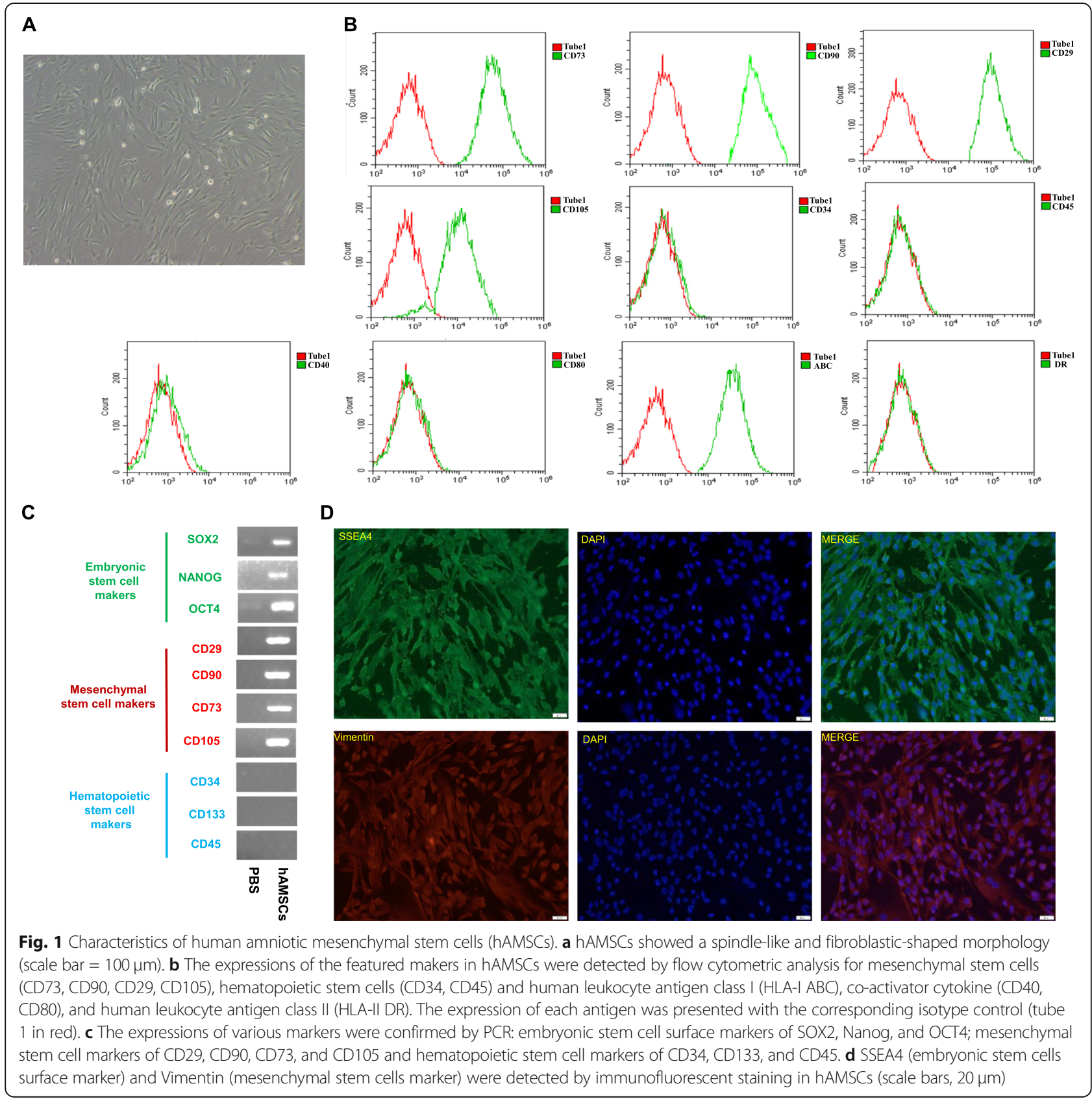


addition, the expressions of ESCs surface marker SSEA4 and MSCs marker Vimentin were also confirmed by immunofluorescent staining (Fig. 1D). All these results indicated that hAMSCs possess the potentials of the multi-lineage differentiation with low immunogenicity.

\section{hAMSCs-CM significantly alleviated high-fat diet-induced obesity}

Our recent work showed that both hAMSCs and their conditioned medium (hAMSCs-CM) were able to attenuate high-fat diet (HFD)-induced hyperglycemia, indicating that their conditioned medium might play a key role in HFD-induced hyperglycemia (unpublished data). Here, we investigated the effects of hAMSCs-CM on HFD-induced obesity in mice. hAMSCs-CM or SFD was intraperitoneally injected weekly into the mice fed with HFD and the body weights were monitored every week. As showed in Fig. 2A, HFD-induced gains of body weights were significantly reduced in the mice treated with hAMSCs-CM compared with mice treated with SFD. The results of GTT and the ITT assays showed that HFD-influenced glucose tolerance and insulin sensitivity were significantly improved in the mice treated with hAMSCs-CM compared with the mice treated with SFD (Fig. 2B, C), further confirming that HFD-induced obesity was accompanied with hyperglycemia and the anti-obesity of hAMSCs-CM might be related with improvement of HFD-induced glucose tolerance and insulin resistance. In addition, hAMSCs-CM remarkably reduced HFD-induced gains of adipose tissues such as epididymal and inguinal white adipose tissues (eWAT and iWAT, Fig. 2D) and protected mice from HFDinduced enlargements of adipocytes in WAT and BAT compared with mice treated with SFD (Fig. 2E-G). Furthermore, the HFD-induced increases of serum TC (Fig. 2H), ALT (Fig. 2I), and LDL-C (Fig. 2K) were markedly reduced in the hAMSCs-CM group compared with the SFD group, suggesting that hAMSCs-CM might improve HFD-induced the dysfunctions of the liver. However, there were no alterations in contents of serum AST (Fig. 2J), TG (Fig. 2L), TP (Fig. 2M), CREA (Fig. 2N), and BUN (Fig. 2O) in various groups after HFD stimulation, suggesting that HFD might not significantly affect kidney functions. All these results indicated that hAMSCs-CM significantly alleviated HFD-induced obesity in mice.

\section{hAMSCs-CM ameliorated HFD-induced obesity by promoting energy expenditure and improving liver functions}

The main feature of obesity is the metabolic disorder which is closely related with the functional alterations of the liver. In order to evaluate the roles of hAMSCs-CM in energy homeostasis, we examined the oxygen consumption $\left(\mathrm{VO}_{2}\right)$, carbon dioxide production $\left(\mathrm{VCO}_{2}\right)$, and food and water intake in mice for $48 \mathrm{~h}$ using TSE PhenoMaster (Germany, TSE Systems). The results showed that HFD-induced reductions in $\mathrm{VO}_{2}, \mathrm{VCO}_{2}$, and water intake were significantly reversed by hAMSCs-CM in mice fed with HFD compared with mice treated with SFD (Fig. 3A-D), indicating that hAMSC-CM effectively alleviated HFD-induced adiposity in mice by increasing energy expenditure.

Next, we examined the alterations of liver morphology and functions. The results showed that hAMSCs-CM markedly reduced HFD-induced gain of liver weights (Fig. 3E) and significantly improved HFD-induced histological alterations of the liver by decreasing lipid droplet deposition and increasing glycogen accumulation (Fig. 3F) which were revealed by HE staining, Oil Red staining, and PAS staining, respectively. Furthermore, the HFD-induced increases of the TC and TG in liver tissues were markedly reduced in the hAMSCs-CM group compared with the SFD group (Fig. 3G). These results suggested that the alterations of liver functions contributed to the HFD-induced obesity in mice.

\section{hAMSCs-CM improved HFD-induced metabolic dysfunctions by enhancing energy expenditure and elevating thermogenesis in mice}

To investigate the roles of hAMSCs-CM in HFDinduced metabolic disorder, the glucose and lipid metabolism and thermogenesis were examined in obese mice. The results showed that the expressions of the glucose transporter GLUT4 in the liver, WAT, BAT, and muscle tissues; PPAR $\alpha$ which is related to lipid metabolism in WAT, BAT, and muscle tissues; and PGC1 $\alpha$ which is a cold-inducible transcription coactivator of adaptive thermogenesis in WAT (Fig. 4A-E) were markedly increased in HFD-fed mice treated with hAMSCs-CM compared with the mice treated with SFD (Fig. 4A-E). These results suggested that hAMSCs-CM reduced the transfer of glucose to lipid generation by promoting glucose utilization and glycogen synthesis. AMP-activated protein kinase (AMPK) is a crucial cellular energy sensor, which takes part in energy balance [29]. Our results also displayed that hAMSCs-CM had a trend of elevating AMPK protein expression in WAT (Fig. 4F-H), suggesting that hAMSCs-CM might reduce the HFD-induced lipid generation by activating AMPK signaling pathway. Akt phosphorylation was a classic insulin activation regulator, involved in glucose metabolism [30]. Furthermore, hAMSCs-CM significantly ameliorated HFDinduced reduction of phosphorylated AKT in WAT (Fig. 4I, J) and liver (Fig. 4I, K). Glycogen synthase kinase $3 \beta$ (GSK3 $\beta$ ) as a AKT downstream regulator plays a role in glycogen metabolism [31]. The results showed that hAMSCs-CM attenuated HFD-induced upregulation of 


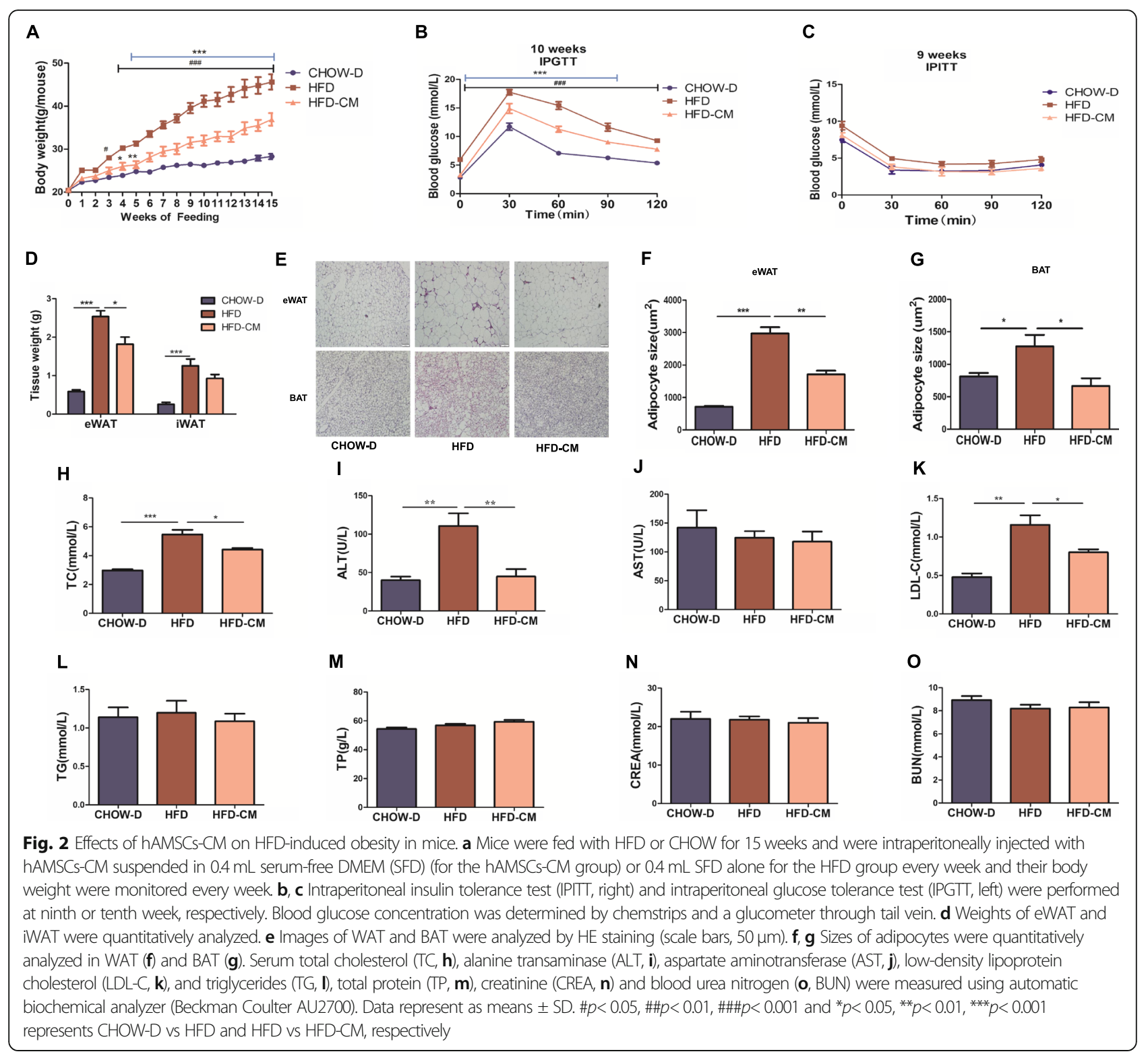

phosphorylated GSK3 $\beta$ in the liver (Fig. $4 \mathrm{~L}-\mathrm{N}$ ). These results further demonstrated that hAMSCs-CM promoted glucose metabolism or glycogen synthesis by activating AKT signaling pathway.

Reduced thermogenesis is a characteristic feature of obesity in mice and humans. UCP-1 is an important thermogenesis protein regulating energy metabolism in BAT. The results showed that UCP-1 was upregulated by IF staining assay (Fig. 4O). Similar results were also observed in protein and mRNA levels (Fig. 4P-R) in BAT. Taken together, these results indicated that hAMSCs-CM significantly improved HFD-induced metabolic dysfunction by promoting energy expenditure and thermogenesis in obese mice.
hAMSCs-CM inhibited adipogenesis through suppressing the differentiation of the pre-adipocytes

The occurrence of obesity is often accompanied with preadipocytes differentiation and adipogenesis. The differentiation from preadipocytes to mature adipocytes is a critical process for obesity development. Therefore, we examined the effects of hAMSCs-CM on the differentiation of 3T3-L1 preadipocytes into adipocytes in vitro. The results showed that hAMSCs-CM significantly inhibited preadipocytes differentiation and lipid accumulation after a 14-day period induction in 3T3-L1 cells (Fig. 5A). In addition, hAMSCs-CM also remarkably suppressed the mRNA expressions of the genes related to adipogenesis such as $\mathrm{AP} 2, \mathrm{C} / \mathrm{EBP} \alpha, \mathrm{PPAR} \gamma$, and 

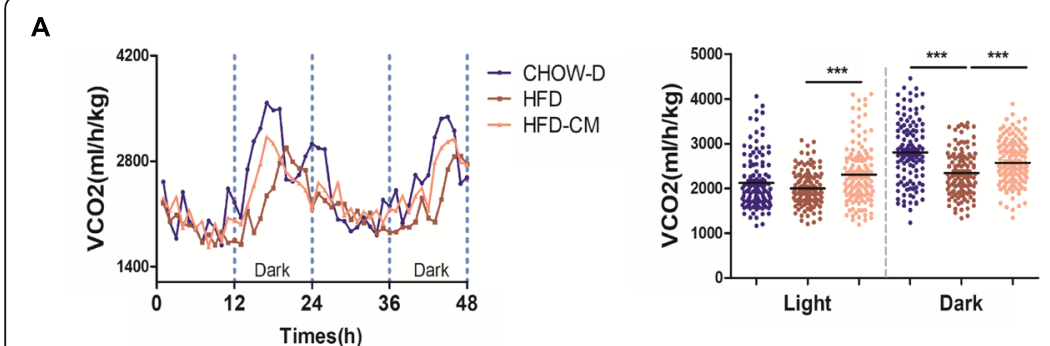

C

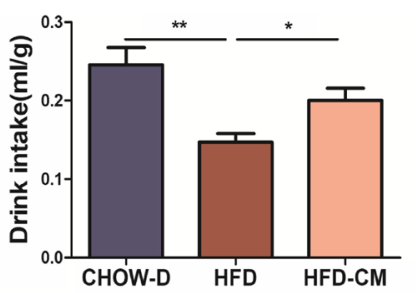

B
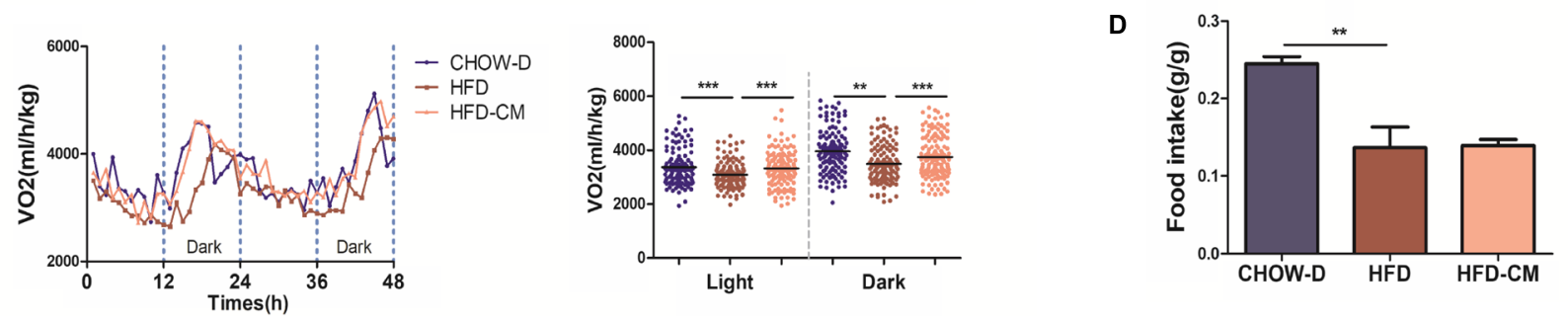

E
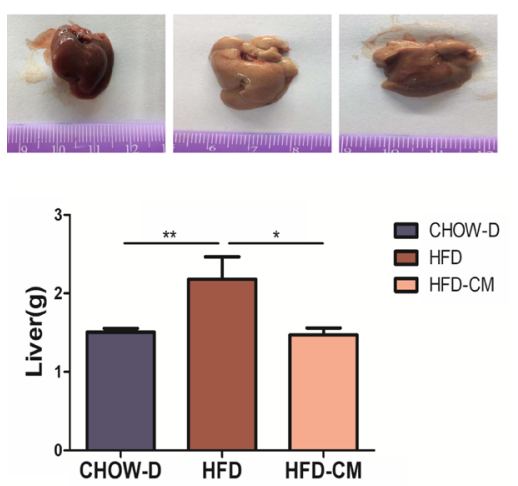

F
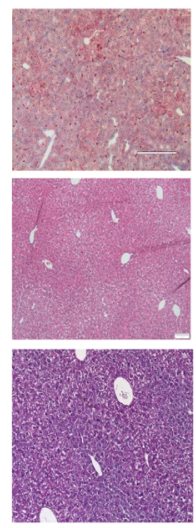

CHOW-D
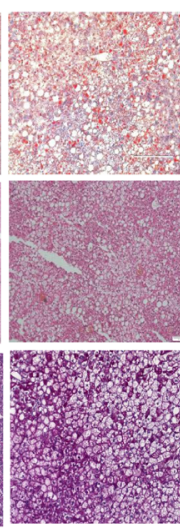

HFD
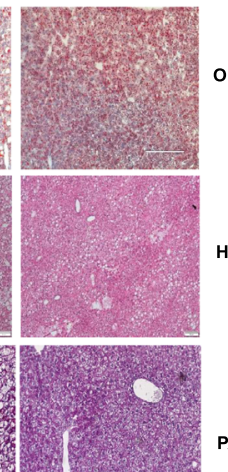

PAS

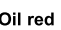

G
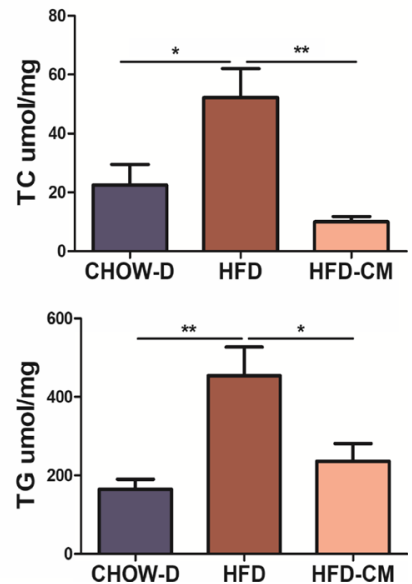

Fig. 3 Effects of hAMSCs-CM on HFD-induced alterations of energy expenditure in mice and lipid accumulation of liver in mice. a-d Mice were placed into the metabolic chambers for more than $24 \mathrm{~h}$ before measuring metabolic parameters. The energy expenditure was evaluated by measuring the carbon dioxide release $\left(\mathrm{VCO}_{2}\right.$, a) oxygen consumption $\left(\mathrm{VO}_{2}, \mathbf{b}\right)$, and water $(\mathbf{c})$ and food $(\mathbf{d})$ intake in mice fed with $\mathrm{HFD}$ and normal diet with or without hAMSCs-CM treatment. e The images of livers were taken in the control group (left), SFD group (medium), and hAMSCs-CM group (right), and the weights of liver tissues were quantitatively analyzed (bottom). $\mathbf{f}$ The effects of hAMSCs-CM on HFD-induced lipid accumulation, alterations of morphology, and the glucagon production were determined by Oil Red staining, HE staining, and periodic acid-Schiff (PAS) staining in liver tissues (scale bars, $200 \mu \mathrm{m}) . \mathbf{g}$ Effects of hAMSCs-CM on HFD-induced the increases of TC and TG contents were determined in liver tissues. Data represent as means \pm SD. $N=5 \sim 6,{ }^{*} p<0.05 ;{ }^{* *} p<0.01,{ }^{* *} p<0.001$

SREBP1 after differential induction (Fig. 5B-E). Furthermore, the protein expressions of C/EBPa, FASN, and PPAR $\gamma$ were also remarkably reduced in the hAMSCsCM group compared with the SFD group (Fig. 5F-I). These results demonstrated that hAMSCs-CM was able to inhibit the preadipocytes differentiation in vitro.

\section{hAMSCs-CM suppressed WAT inflammation by activating STAT3/ARG-1 pathway or altering the macrophage polarization in the obese mice}

Obesity is characterized as a chronic low-degrade inflammation. The adipokines secreted from adipose tissues were able to recruit a large number of macrophages to the adipose tissues and lead to inflammation. We further evaluated the roles of hAMSCs-CM in HFDinduced macrophage-mediated inflammation by examination of macrophages infiltration and inflammatory cytokines from epididymal adipose tissues in mice. Considering that macrophages polarization contributes to WAT inflammation, the inflammatory cytokines secreted from the M1 and M2 macrophages were detected by qPCR. The results showed that hAMSCs-CM remarkably reduced the mRNA levels of proinflammatory cytokines CD11C and TNF $\alpha$, but enhanced that of antiinflammatory cytokines ARG-1 and CD209A in WAT of the mice fed with HFD compared with the SFD group 


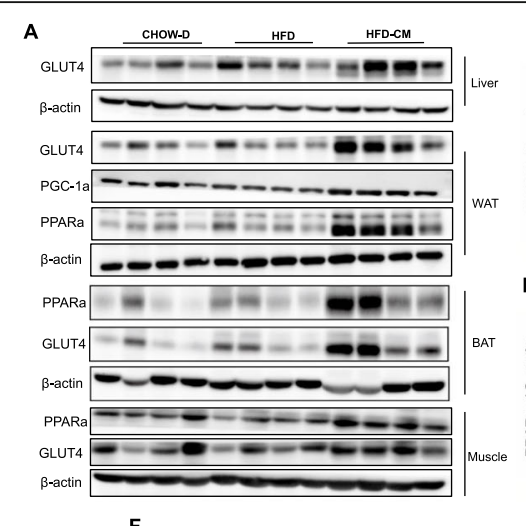

$\mathbf{F}$

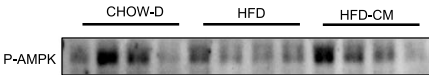

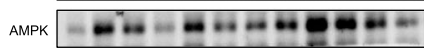

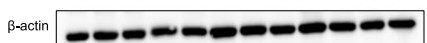

I CHOW-D HFD HFD-CM P-AKT

AKT -

$\beta$-actin

Р-АКT

AKT

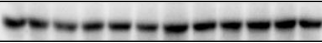

$\beta$-actin
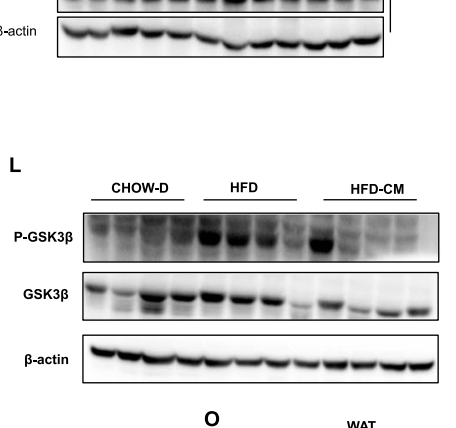

0
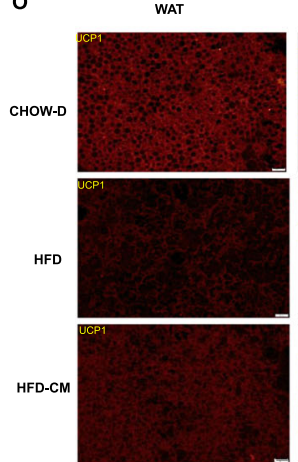

P

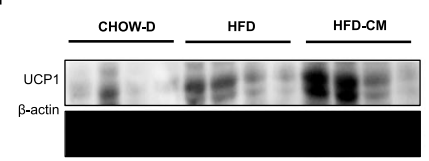

B
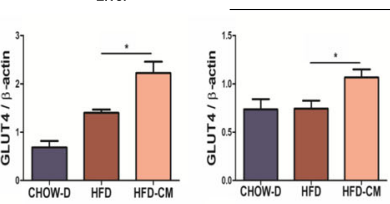

BAT
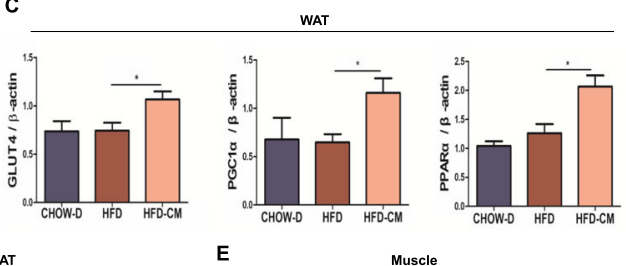

E

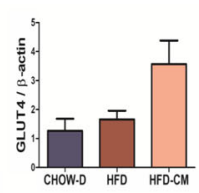

Muscle

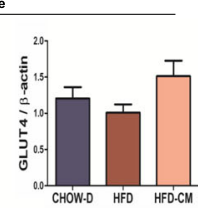

G
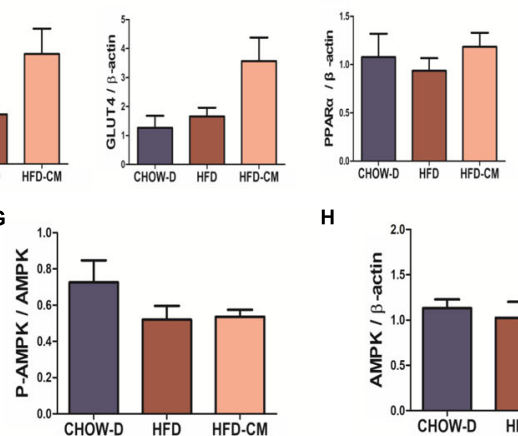

$\mathrm{H}$
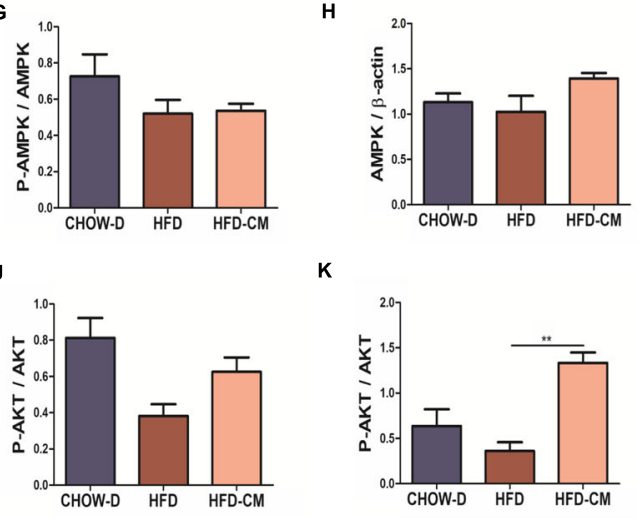

M
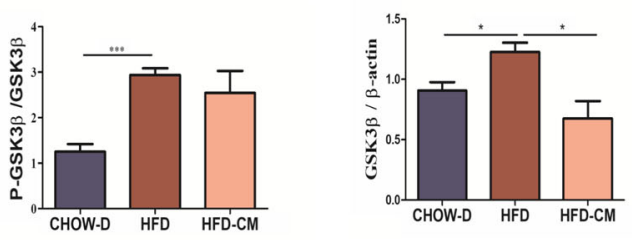

Liver
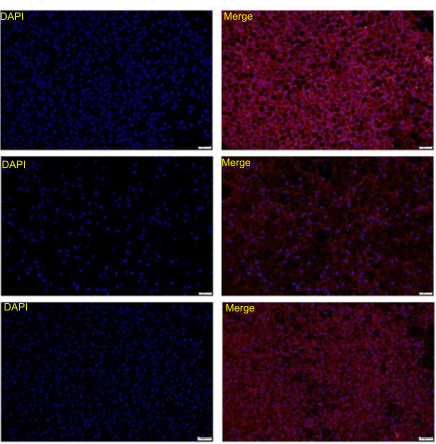

Q

$\mathbf{R}$
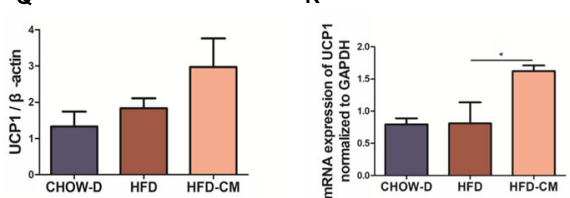

Fig. 4 (See legend on next page.) 
(See figure on previous page.)

Fig. 4 Effects of hAMSCs-CM on the expressions of the proteins related with lipid and glucose metabolism, and thermogenesis in multiple tissues of obese mice. a Expressions of GLUT4 in liver, PPARa and GLUT4 in WAT\&BAT\&muscle, and PGC-1a in WAT were examined by western blot. b-e The protein expressions of GLUT4 in the liver (b) \& WAT (c) \& BAT (d) \& muscle (e), PPARa in WAT (c) \& BAT (d) \& muscle (e), and PGC-1a in WAT (c) were quantitatively analyzed. $\mathbf{f}-\mathbf{h}$ the protein expressions of P-AMPK and AMPK in WAT were determined by western blot (f) and quantitative analyses $(\mathbf{g}, \mathbf{h})$. $\mathbf{i}-\mathbf{k}$ The protein expressions of P-AKT and AKT in WAT and liver were determined by western blot (i) and quantitative analyses $(\mathbf{j}, \mathbf{k})$. I-n the protein expressions of P-GSK3 $\beta$ and GSK3 $\beta$ in the liver were determined by western blot (I) and quantitative analyses ( $\mathbf{m}, \mathbf{n})$. $\mathbf{o}$ UCP1 expression was determined by immunofluorescent staining in BAT (scale bars, $20 \mu \mathrm{m}$ ). $\mathbf{p}$, q The expression of UCP1 protein was determined by western blot (p) and quantitative analysis (q) in BAT. $\mathbf{r}$ UCP1 mRNA expression was also examined by RT-PCR in BAT. $\beta$-actin was served as the loading control. Data represent as means \pm SD. ${ }^{*} p<0.05 ;{ }^{* *} p<0.01$, ${ }^{* *} p<0.001$

(Fig. 6A-D). As shown in Fig. 6E, hAMSCs-CM dramatically reduced HFD-induced F4/80 positive macrophages in WAT, in which the macrophages displayed classical crown-like structures. In addition, the p-STAT3/ARG-1 signaling pathway was also detected in WAT. The results showed that HFD significantly inhibited the protein expression of ARG-1 and increased the phosphorylation of STAT3 although the total protein levels of STAT3 were not altered. In comparison, hAMSCs-CM effectively reversed HFD-induced decreases of ARG-1 and increase of the phosphorylated STAT3 (Fig. 6F-H), suggesting that the anti-obesity of hAMSCs-CM might be involved in their anti-inflammation.

Furthermore, the effects of hAMSCs-CM on macrophages polarization were determined in RAW264.7 macrophages that were induced into M1 or M2 macrophage with LPS+IFNY or IL4, respectively. The results showed that hAMSCs-CM inhibited the transcripts of M1 inflammation cytokines IL- 6 and IL-1 $\beta$ and increased that of M2 anti-inflammation cytokines IL10 and ARG-1 in RAW264.7 cells (Fig. 6I-L). These results indicated that hAMSCs-CM might inhibit HFD-induced adipose tissue

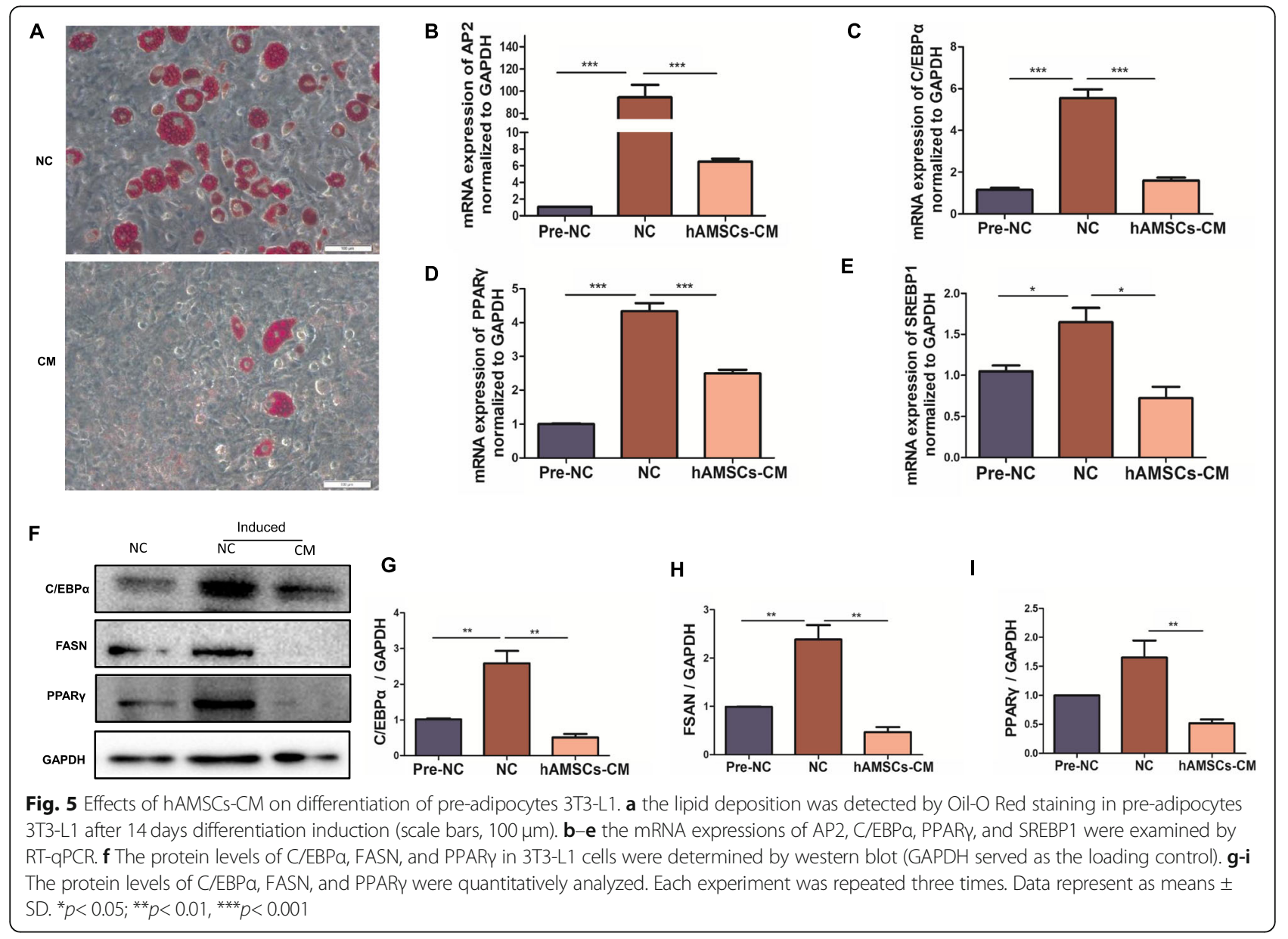




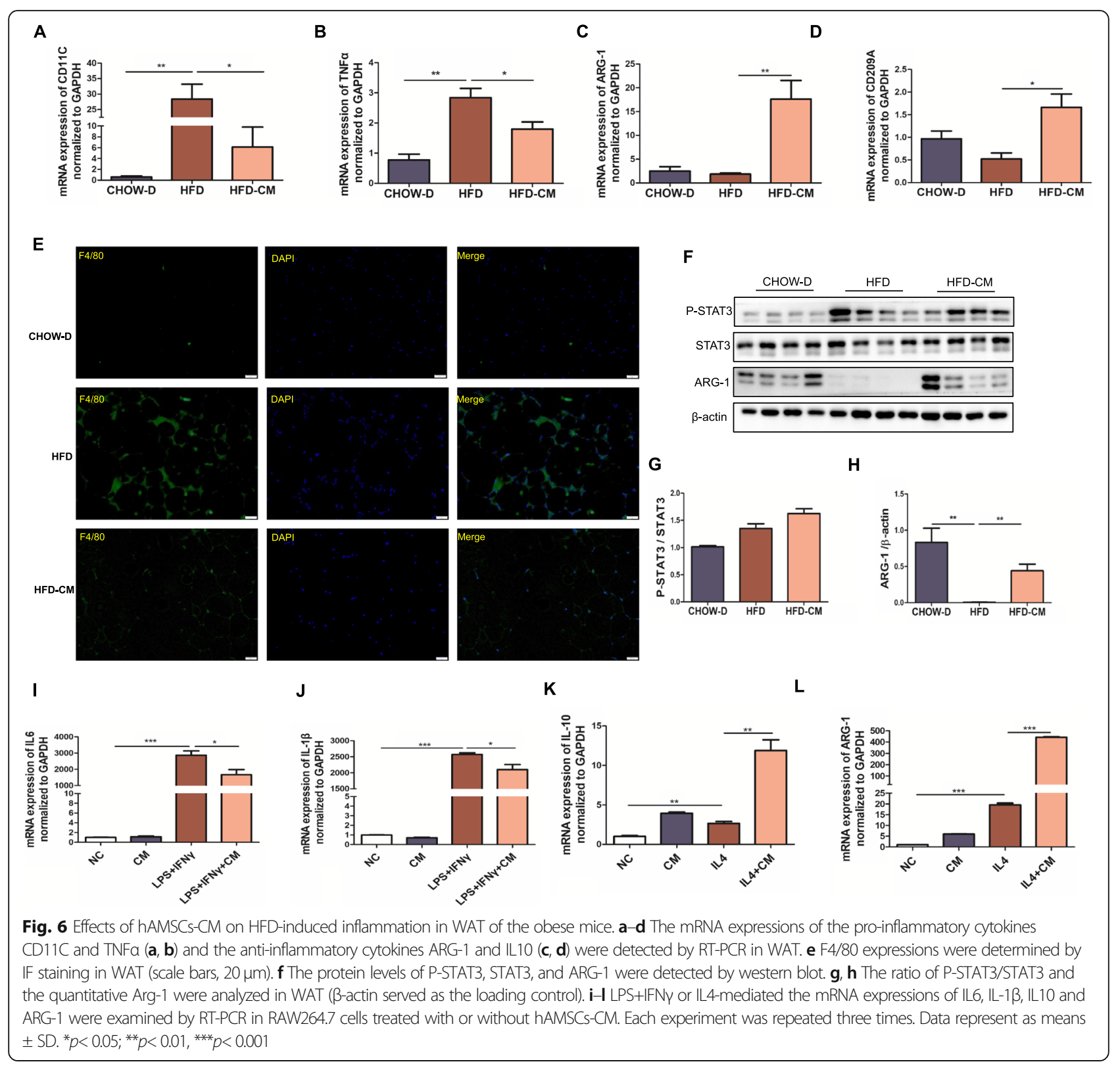

inflammation by activating STAT3/ARG-1 pathway or altering the macrophage polarization in HFD-induced obese mice.

\section{Discussion}

Studies demonstrated that hAMSCs have a great potential for stem cell-based therapy in many diseases due to their pluripotency, low immunogenicity, no tumorigenicity, potent paracrine effects, and no ethical concern [23]. We previously observed that both hAMSCs and their CM efficiently repaired skin injury [24], inhibited hepatocellular carcinoma [25], and alleviated HFDinduced hyperglycemia in mice (unpublished data), suggesting that hAMSCs-CM plays a key role in the cells- based therapy by their paracrine effects through afftecting immunoregulation and anti-inflammation. It has been reported that exosomes from adipose MSCs ameliorated HFD-induced obesity in mice through antiinflammation, improving insulin sensitivity and decreasing hepatic steatosis [27]. In the present study, we observed that hAMSCs-CM was able to improve HFDinduced metabolic disorders by reducing weight gain, improving insulin sensitivity, alleviating hepatic steatosis, and enhancing energy expenditure. In addition, our results also showed that hAMSCs-CM-mediated the inhibition of adipogenesis, enhancements of glucose metabolism and glycogen synthesis, and antiinflammation contributed to their anti-obesity in HFD- 
induced obese mice. Furthermore, we demonstrated that the anti-obesity of hAMSCs-CM might be related to their multiple molecular mechanisms which were involved in activating AKT/GLUT4-mediated glucose metabolism, enhancing UCP1/PPAR $\alpha$-mediated energy expenditure, and increasing STAT3-ARG1-mediated M2 macrophage polarization during the development of obesity.

Obesity is characterized with hypertrophic adipocytes along with increased numbers of mature adipocytes which are differentiated from pre-adipocytes. PPAR $\gamma$ and $\mathrm{C} / \mathrm{EBP} \alpha$ are main regulators during early period of adipogenesis $[32,33]$. It has been reported that downregulation of PPAR $\gamma$ and C/EBP $\alpha$ expressions ameliorated HFD-induced obesity through inhibiting adipogenesis [34]. Our results showed that hAMSCs-CM inhibited the differentiation of 3T3-L1 pre-adipocytes into mature adipocytes, and the mechanism might be related to hAMSCs-CM-induced downregulations of the lipogenesis genes such as PPAR $\gamma, \mathrm{C} / \mathrm{EBP} \alpha, \mathrm{FAS}, \mathrm{AP} 2$, and SREBP1.

PPAR $\alpha$ is highly expressed in liver, muscle, BAT, and heart and plays an important role in energy homeostasis [35]. PGC-1 $\alpha$ usually forms a complex with PPAR $\alpha$ to regulate many biological processes. Decreased PPAR $\alpha$ and PGC- $1 \alpha$ could downregulate the expressions of the genes related to the impairment of heart function and fatty acid oxidation. PPAR- $\alpha$ inhibitors can restore cardiac energy homeostasis and function [36]. Lipid accumulation in adipose tissues and low energy expenditure are characteristic features of obesity. Our study showed that hAMSCs-CM promoted energy expenditure by increasing $\mathrm{VO}_{2}, \mathrm{VCO}_{2}$, and water intake in HFD conditions, which was consistent with the upregulations of PPAR $\alpha$, PGC- $1 \alpha$ in adipose tissues.

Lipid and glucose metabolism play a critical role in the energy homeostasis of adipose tissues [37]. GLUT4 is a key glucose transporter for regulating glucose intake in adipose tissues. Downregulation or disruption of GLUT4 was able to cause insulin tolerance, which further leads to severe diabetes and obesity [38]. AKT, a Serine/ Threonine kinase which is activated by insulin growth cytokines, participates in lipid and glucose metabolism [30]. Our finding further demonstrated that hAMSCs$\mathrm{CM}$ elevated lipid and glucose utilization by activating AKT phosphorylation. BAT contains abundant mitochondria and is acknowledged as thermogenesis organ. Studies indicated that PPAR $\alpha$ activated UCP1 and promoted the expressions of the genes related to thermogenesis to repress HFD-induced obesity [39]. Study also showed that there were some "beige adipocytes" which were similar to brown adipocyte, in WAT, in which these special adipocytes were able to elevate the expressions of the thermogenesis genes such as UCP1, PPAR $\alpha$,
PGC1 $\alpha$, Cidea, CPT1 and HSL to promote energy expenditure [40]. In the present study, we observed that hAMSCs-CM promoted UCP1 expression in BAT, indicating that the anti-obesity of hAMSCs-CM might be partially related to their promoting energy expenditure.

Obesity is a complicated metabolic syndrome in which the initiation and development of obesity may be associated with the disorders of the multiple organs/tissues in the body. Studies showed that human umbilical cordderived MSCs exosomes improved insulin resistance and inflammation in type 2 diabetes rats [41], and the cytokines secreted from MSCs enhanced angiogenesis to protect kidney injury and wound healing through promoting angiogenesis [42, 43], suggesting that the cytokines or exosomes secreted from stem cells may play a key role in treating diseases. In the present study, we demonstrated that the anti-obesity of hAMSCs-CM was associated with their inhibiting lipid accumulation or adipogenesis, alleviating inflammation in adipose tissues, and promoting energy expenditure. However, due to the complexity of obesity, it is possible that multiple proteins or nuclear acid molecules in hAMSCs-CM may play the critical roles in their anti-obesity. Obviously, the key factors in hAMSCs-CM should be further identified in the future.

\section{Conclusion}

Our study demonstrated that hAMSCs-CM significantly alleviated HFD-induced obesity in mice through suppressing lipid accumulation and adipogenesis in adipose tissues and liver, enhancing energy expenditure in multiple organs such as liver and muscle, and alleviating inflammation in adipose tissues. The underlying mechanisms of the anti-obesity of hAMSCs-CM might be involved in inhibiting PPARy and C/ EBP $\alpha$-mediated lipid synthesis and adipogenesis, promoting GLUT4-mediated glucose metabolism, elevating UCP1/ PPAR $\alpha / P G C 1 \alpha$-mediated energy expenditure, and enhancing STAT3-ARG1-mediated M2-type macrophage polarization during the development of obesity. Obviously, our findings provided strong evidences that hAMSCs-CM has a great potential for the treatment of the metabolic disorders such as obesity clinically. Certainly, the key factors or components of the exosomes from hAMSCs-CM for their anti-obesity should be identified in the future.

\footnotetext{
Abbreviations

hAMSCs: Human amniotic mesenchymal stem cells; hAMSCs-CM: Human amniotic mesenchymal stem cells-derived conditioned medium; hADSCs: Human amnion-derived stem cells; Sox2: SRY-box transcription factor 2; Oct-4: Octamer-binding transcription factor 4; SSEA-4: Stage-specific embryonic antigen 4; SFD: Serum-free DMEM; CHOW-D: Normal chow diet; ALT: Serum alanine transaminase; AST: Aspartate aminotransferase; TC: Total cholesterol; TG: Triglyceride; HDL-C: High-density lipoprotein cholesterol; LDL-C: Low-density lipoprotein cholesterol; TP: Total protein; CREA: Creatinine; BUN: Blood urine nitrogen; IF: Immunofluorescence ; HE: Hematoxylin-eosin; PAS: Periodic acid-schiff; IBMX: 3-Isobutyl-1methylxanthine
} 


\section{Supplementary Information}

The online version contains supplementary material available at https://doi. org/10.1186/s13287-021-02437-z.

Additional file 1: Table S1. The primer sequences for $q R T-P C R$.

\section{Acknowledgements}

We are grateful to the donors for kindly providing placenta from the First Affiliated Hospital of Nanchang University and the members of the Transgenic Mouse Facility in the Institute of Translational Medicine of Nanchang University for animal housing.

\section{Authors' contributions}

H.L.T. and X.H.G.: performance of experiments, collection and/or assembly of data, data analysis and interpretation, manuscript writing; M.H. and J.W.: Provision of study material, collection and/or assembly of data; R.Z.L., H.H.D., Z.P.Y., X.Y.W., L.F.W., and Y.F.X.: collection and/or assembly of data; H.B.X. and K.Y.D.: conception and design, financial support, manuscript revision. All authors read and approved the final version of the manuscript.

\section{Funding}

This work was supported by the National Natural Science Foundation of China $(81873659,81800432,82000354,81760140,81970256,81901546)$ and Jiangxi Provincial Department of Science and Technology, China (20165BCD41001 and 20181BAB205009).

\section{Availability of data and materials}

The datasets used and/or analyzed during the current study are available from the corresponding author upon reasonable request.

\section{Declarations}

\section{Ethics approval and consent to participate}

All protocols involved with human samples in the study were approved by the Ethics Committee of the First Affiliated Hospital of Nanchang University All procedures involving animals were approved by the Institutional Animal Care and Use Committees at Nanchang University and conducted in accordance with the national guidelines on animal care.

\section{Consent for publication}

Not applicable.

\section{Competing interests}

The authors declare that they have no competing interests.

\section{Author details}

${ }^{1}$ The National Engineering Research Center for Bioengineering Drugs and the Technologies, Institute of Translational Medicine, Nanchang University, No. 1299 Xuefu Road, Honggutan District, Nanchang 330031, China. ${ }^{2}$ School of Pharmacy, Nanchang University, Nanchang, China. ${ }^{3}$ School of Life and Science, Nanchang University, Nanchang, China.

\section{Received: 8 April 2021 Accepted: 7 June 2021}

\section{Published online: 26 June 2021}

\section{References}

1. Targher G, Byrne CD. Obesity: Metabolically healthy obesity and NAFLD. Nat Rev Gastroenterol Hepatol. 2016;13(8):442-4. https://doi.org/10.1038/nrga stro.2016.104.

2. Kotsis V, Nilsson P, Grassi G, Mancia G, Redon J, Luft F, et al. New developments in the pathogenesis of obesity-induced hypertension. J Hypertens. 2015;33(8):1499-508. https://doi.org/10.1097/HJH. 0000000000000645 .

3. Bray GA, Heisel WE, Afshin A, Jensen MD, Dietz WH, Long M, et al. The Science of Obesity Management: An Endocrine Society Scientific Statement. Endocrine Rev. 2018;39(2):79-132. https://doi.org/10.1210/er.2017-00253.

4. Desvergne B, Wahli W. Peroxisome proliferator-activated receptors: nuclear control of metabolism. Endocrine Rev. 1999;20(5):649-88. https://doi.org/1 0.1210/edrv.20.5.0380.
5. Lefebvre P, Chinetti G, Fruchart JC, Staels B. Sorting out the roles of PPAR alpha in energy metabolism and vascular homeostasis. J Clin Invest. 2006; 116(3):571-80. https://doi.org/10.1172/JCI27989.

6. Brocker CN, Patel DP, Velenosi TJ, Kim D, Yan T, Yue J, et al. Extrahepatic PPARa modulates fatty acid oxidation and attenuates fasting-induced hepatosteatosis in mice. J Lipid Res. 2018;59(11):2140-52. https://doi.org/1 $0.1194 /$ jlr.M088419.

7. Pal M, Wunderlich CM, Spohn G, Brönneke HS, Schmidt-Supprian M, Wunderlich FT. Alteration of JNK-1 signaling in skeletal muscle fails to affect glucose homeostasis and obesity-associated insulin resistance in mice. Plos One. 2013;8(1):e54247. https://doi.org/10.1371/journal.pone.0054247.

8. Esteve RM. Adipose tissue: cell heterogeneity and functional diversity. Endocrinol Nutr. 2014;61(2):100-12. https:/doi.org/10.1016/j.endonu.2013.03.011.

9. Jung UJ, Choi MS. Obesity and its metabolic complications: the role of adipokines and the relationship between obesity, inflammation, insulin resistance, dyslipidemia and nonalcoholic fatty liver disease. Int J Mol Sci. 2014;15(4):6184-223. https://doi.org/10.3390/ijms15046184.

10. van Marken Lichtenbelt WD, Vanhommerig JW, Smulders NM, Drossaerts JM, Kemerink GJ, Bouvy ND, et al. Cold-activated brown adipose tissue in healthy men. N Engl J Med. 2009;360(15):1500-8. https://doi.org/10.1056/ NEJMoa0808718.

11. Chouchani ET, Kazak L, Spiegelman BM. New Advances in Adaptive Thermogenesis: UCP1 and Beyond. Cell Metab. 2019;29(1):27-37. https://doi. org/10.1016/j.cmet.2018.11.002

12. Betz MJ, Enerbäck S. Targeting thermogenesis in brown fat and muscle to treat obesity and metabolic disease. Nat Rev Endocrinol. 2018;14(2):77-87. https://doi.org/10.1038/nrendo.2017.132.

13. Spiegelman BM, Hu E, Kim JB, Brun R. PPAR gamma and the control of adipogenesis. Biochimie. 1997;79(2-3):111-2. https://doi.org/10.1016/50300 9084(97)81500-3.

14. Galbraith L, Leung HY, Ahmad I. Lipid pathway deregulation in advanced prostate cancer. Pharmacol Res. 2018;131:177-84. https://doi.org/10.1016/j. phrs.2018.02.022.

15. Catrysse L, van Loo G. Adipose tissue macrophages and their polarization in health and obesity. Cell Immunol. 2018;330:114-9. https://doi.org/10.1016/j. cellimm.2018.03.001.

16. Zhao XY, Li S, DelProposto JL, Liu T, Mi L, Porsche C, et al. The long noncoding RNA BInc1 orchestrates homeostatic adipose tissue remodeling to preserve metabolic health. Mol Metab. 2018;14:60-70. https://doi.org/10.1 016/j.molmet.2018.06.005.

17. Hotamisligil GS. Inflammation and metabolic disorders. Nature. 2006; 444(7121):860-7. https://doi.org/10.1038/nature05485.

18. Vizoso FJ, Eiro N, Cid S, Schneider J, Perez-Fernandez R. Mesenchymal Stem Cell Secretome: Toward Cell-Free Therapeutic Strategies in Regenerative Medicine. Int J Mol Sci. 2017;18(9):1852. https://doi.org/10.3390/ijms18091852.

19. Gnecchi M, Danieli P, Malpasso G, Ciuffreda MC. Paracrine Mechanisms of Mesenchymal Stem Cells in Tissue Repair. Methods Mol Biol. 2016;1416:123-46.

20. Won CH, Park GH, Wu X, Tran TN, Park KY, Park BS, et al. The Basic Mechanism of Hair Growth Stimulation by Adipose-derived Stem Cells and Their Secretory Factors. Curr Stem Cell Res Ther. 2017;12(7):535-43. https:// doi.org/10.2174/1574888X12666170829161058.

21. ShamsEldeen AM, Ashour H, Shoukry HS, Fadel M, Kamar SS, Aabdelbaset M, et al. Combined treatment with systemic resveratrol and resveratrol preconditioned mesenchymal stem cells, maximizes antifibrotic action in diabetic cardiomyopathy. J Cell Physiol. 2019;234(7):10942-63. https://doi. org/10.1002/jcp.27947

22. Volarevic V, Nurkovic J, Arsenijevic N, Stojkovic M. Concise review: Therapeutic potential of mesenchymal stem cells for the treatment of acute liver failure and cirrhosis. Stem Cells. 2014;32(11):2818-23.

23. Liu QW, Huang QM, Wu HY, Zuo GS, Gu HC, Deng KY, et al. Characteristics and Therapeutic Potential of Human Amnion-Derived Stem Cells. Int J Mo Sci. 2021;22(2):970.

24. Li JY, Ren KK, Zhang WJ, Xiao L, Wu HY, Liu QY, et al. Human amniotic mesenchymal stem cells and their paracrine factors promote wound healing by inhibiting heat stress-induced skin cell apoptosis and enhancing their proliferation through activating PI3K/AKT signaling pathway. Stem cell Rese Ther. 2019;10(1):247. https://doi.org/10.1186/s13287-019-1366-y.

25. Liu QW, Li JY, Zhang XC, Liu Y, Liu QY, Xiao L, et al. Human amniotic mesenchymal stem cells inhibit hepatocellular carcinoma in tumour-bearing mice. J Cell Mol Med. 2020:24(18):10525-41. https://doi.org/10.1111/jcmm.1 5668. 
26. Zhao H, Shang Q, Pan Z, Bai Y, Li Z, Zhang H, et al. Exosomes From Adipose-Derived Stem Cells Attenuate Adipose Inflammation and Obesity Through Polarizing M2 Macrophages and Beiging in White Adipose Tissue. Diabetes. 2018;67(2):235-47. https://doi.org/10.2337/db17-0356.

27. Shree N, Bhonde RR. Conditioned Media From Adipose Tissue Derived Mesenchymal Stem Cells Reverse Insulin Resistance in Cellular Models. J Cell Biochem. 2017;118(8):2037-43. https://doi.org/10.1002/jcb.25777.

28. Díaz-Prado S, Muiños-López E, Hermida-Gómez T, Rendal-Vázquez ME, Fuentes-Boquete I, de Toro FJ, et al. Isolation and characterization of mesenchymal stem cells from human amniotic membrane. Tissue Eng Part C Methods. 2011;17(1):49-59. https://doi.org/10.1089/ten.tec.2010.0136.

29. Hardie DG, Ross FA, Hawley SA. AMPK: a nutrient and energy sensor that maintains energy homeostasis. Nat Rev Mol Cell Biol. 2012;13(4):251-62. https://doi.org/10.1038/nrm3311.

30. Moreno-Aliaga MJ, Pérez-Echarri N, Marcos-Gómez B, Larequi E, Gil-Bea FJ, Viollet B, et al. Cardiotrophin-1 is a key regulator of glucose and lipid metabolism. Cell Metab. 2011;14(2):242-53. https://doi.org/10.1016/j.cmet.2 011.05.013.

31. Ciaraldi TP, Carter L, Mudaliar S, Henry RR. GSK-3beta and control of glucose metabolism and insulin action in human skeletal muscle. Mol Cell Endocrinol. 2010;315(1-2):153-8. https://doi.org/10.1016/j.mce.2009.05.020.

32. Zhuang H, Zhang X, Zhu C, Tang X, Yu F, Shang GW, et al. Molecular Mechanisms of PPAR- $\gamma$ Governing MSC Osteogenic and Adipogenic Differentiation. Curr Stem Cell Res Ther. 2016;11(3):255-64. https://doi.org/1 0.2174/1574888X10666150531173309.

33. de Ferranti S, Mozaffarian D. The perfect storm: obesity, adipocyte dysfunction, and metabolic consequences. Clin Chem. 2008;54(6):945-55. https://doi.org/10.1373/clinchem.2007.100156.

34. Lai CS, Chen YY, Lee PS, Kalyanam N, Ho CT, Liou WS, et al. Bisdemethoxycurcumin Inhibits Adipogenesis in 3T3-L1 Preadipocytes and Suppresses Obesity in High-Fat Diet-Fed C57BL/6 Mice. J Agric Food Chem. 2016;64(4):821-30. https://doi.org/10.1021/acs.jafc.5b05577.

35. Bougarne N, Weyers B, Desmet SJ, Deckers J, Ray DW, Staels B, et al. Molecular Actions of PPARa in Lipid Metabolism and Inflammation. Endocrine Rev. 2018;39(5):760-802. https://doi.org/10.1210/er.2018-00064.

36. Haemmerle G, Moustafa T, Woelkart G, Büttner S, Schmidt A, van de Weijer $T$, et al. ATGL-mediated fat catabolism regulates cardiac mitochondrial function via PPAR-a and PGC-1. Nat Med. 2011;17(9):1076-85. https://doi. org/10.1038/nm.2439.

37. Wang C, Huang Z, Du Y, Cheng Y, Chen S, Guo F. ATF4 regulates lipid metabolism and thermogenesis. Cell Res. 2010;20(2):174-84. https://doi. org/10.1038/cr.2010.4.

38. Moraes-Vieira PM, Saghatelian A, Kahn BB. GLUT4 Expression in Adipocytes Regulates De Novo Lipogenesis and Levels of a Novel Class of Lipids With Antidiabetic and Anti-inflammatory Effects. Diabetes. 2016;65(7):1808-15. https://doi.org/10.2337/db16-0221.

39. Pan MH, Koh YC, Lee TL, Wang B. Resveratrol and Oxyresveratrol Activate Thermogenesis via Different Transcriptional Coactivators in High-Fat DietInduced Obese Mice. J Agric Food Chem. 2019;67(49):13605-16. https://doi. org/10.1021/acs.jafc.9b05963.

40. Lee HH, An SM, Ye BJ, Lee JH, Yoo EJ, Jeong GW, et al. TonEBP/NFAT5 promotes obesity and insulin resistance by epigenetic suppression of white adipose tissue beiging. Nat Commun. 2019;10(1):3536. https://doi.org/10.103 8/s41467-019-11302-w.

41. Sun X, Hao H, Han Q, Song X, Liu J, Dong L, et al. Human umbilical cordderived mesenchymal stem cells ameliorate insulin resistance by suppressing NLRP3 inflammasome-mediated inflammation in type 2 diabetes rats. Stem Cell Res Ther. 2017;8(1):241. https://doi.org/10.1186/s132 87-017-0668-1.

42. Yun CW, Lee SH. Potential and Therapeutic Efficacy of Cell-based Therapy Using Mesenchymal Stem Cells for Acute/chronic Kidney Disease. Int J Mol Sci. 2019;20(7):1619.

43. Ariyanti AD, Zhang J, Marcelina O, Nugrahaningrum DA, Wang G, Kasim V, et al. Salidroside-Pretreated Mesenchymal Stem Cells Enhance Diabetic Wound Healing by Promoting Paracrine Function and Survival of Mesenchymal Stem Cells Under Hyperglycemia. Stem Cells Transl Med. 2019;8(4):404-14. https://doi.org/10.1002/sctm.18-0143.

\section{Publisher's Note}

Springer Nature remains neutral with regard to jurisdictional claims in published maps and institutional affiliations.

Ready to submit your research? Choose BMC and benefit from:

- fast, convenient online submission

- thorough peer review by experienced researchers in your field

- rapid publication on acceptance

- support for research data, including large and complex data types

- gold Open Access which fosters wider collaboration and increased citations

- maximum visibility for your research: over $100 \mathrm{M}$ website views per year

At BMC, research is always in progress.

Learn more biomedcentral.com/submissions 